\title{
UTILISATION OF MODELING, STRESS ANALYSIS, KINEMATICS OPTIMISATION, AND HYPOTHETICAL ESTIMATION OF LIFETIME IN THE DESIGN PROCESS OF MOBILE WORKING MACHINES
}

\author{
Gregor IZRAEL, MSc., PhD., Juraj BUKOVECZKY, Prof., PhD., Ladislav GULAN, Prof., \\ PhD.)
}

Slovak University of Technology in Bratislava, Faculty of Mechanical Engineering Námestie Slobody 1, 81231 Bratislava 1

\begin{abstract}
The contribution deals with several methods used in the construction process such as model creation, verification of technical parameters of the machine, and life estimation of the selected modules. Determination of life cycle for mobile working machines, and their carrying modules respectively by investigation and subsequent processing of results gained by service measurements. Machine life claimed by a producer is only relative, because life of these machines depends not only on the way of work on that particular machine but also the state of material which is manipulated by the machine and in great extent the operator, their observance of security regulations, and prescribed working conditions.
\end{abstract}

Key words: load spectrum, lifetime, verification tests, stress analysis

\section{INTRODUCTION}

Use of modern, computer-aided modeling system allows for time reduction in the complex design of mobile working machinery. Design programs allow the creation of complete 3D models of the designed machine or machine parts. They also perform stress analysis and optimization of the kinematic assemblies. The work efficiency in the design stage is increased by use of interactive programs and total costs for the development of machines are reduced as well. An important part of the development of new designs is the verification of the proposed basic technical parameters which represent the force influence on the working tool, including their limit states. In operating practice, the limiting factor of a machines life is the fatigue damage of their carrying parts. It is therefore necessary to pay attention to fatigue limits in the design process. Usually various hypotheses of fatigue damage cumulating are used to estimate working life. Acquired results are subject to careful analysis, because they can lead to significantly different conclusions.

\section{MODELING OF THE WORKING DEVICE}

Computer aided design software reduces the design time, but also makes it easier to perform corrections and provide a complex 3D model of the proposed machine or its parts. CATIA, SolidWorks, Solid Edge, Pro / ENGINEER, Autodesk Inventor are the most commonly used programs in practice. The rotary front loader of PPS Group's company in Detva with the model number HON 200 was also designed using 3D modeling software. A complete virtual model of the loader was created, including its working device (Fig. 1). 


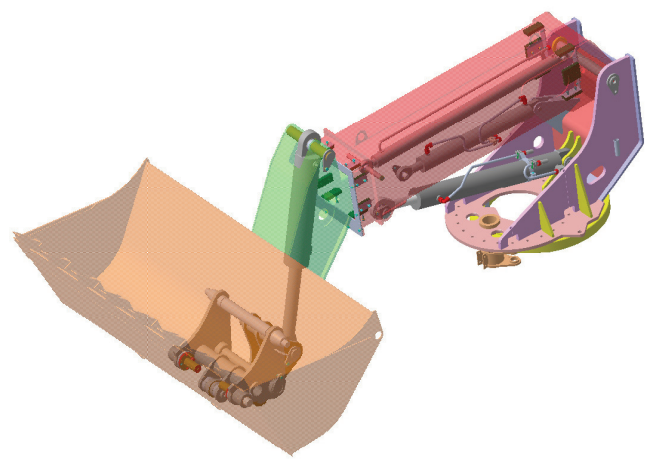

Fig. 1 - Telescopic working device of loader "hon 200t"

\section{STRESS ANALYSIS AND OPTIMISATION}

The created model served as a basis for stress analysis by use of the finite element method. An example output can be seen in Fig. 2 which represents the stresses in particular locations of the working device. Based on the results of the analysis a strength verification of the prototype can be performed to obtained a complex overview of the structure stresses, as well as the nodes with the highest stress concentration. Optimization of selected components for kinematic analysis of assemblies can also be performed. The aforementioned software products make further decision in the design stage of prototype easier. MSC.ADAMS is a widely used program for optimization tasks. In the design stage of the loader HON 200 (using program MSC.ADAMS) the parametric model of telescopic boom was created through optimization of variable coordinates in the main points of kinematics to meet the required criteria. For example, the process of optimized for tearout force depends on the angle of the working tool as shown in Fig. 3, [1]. 


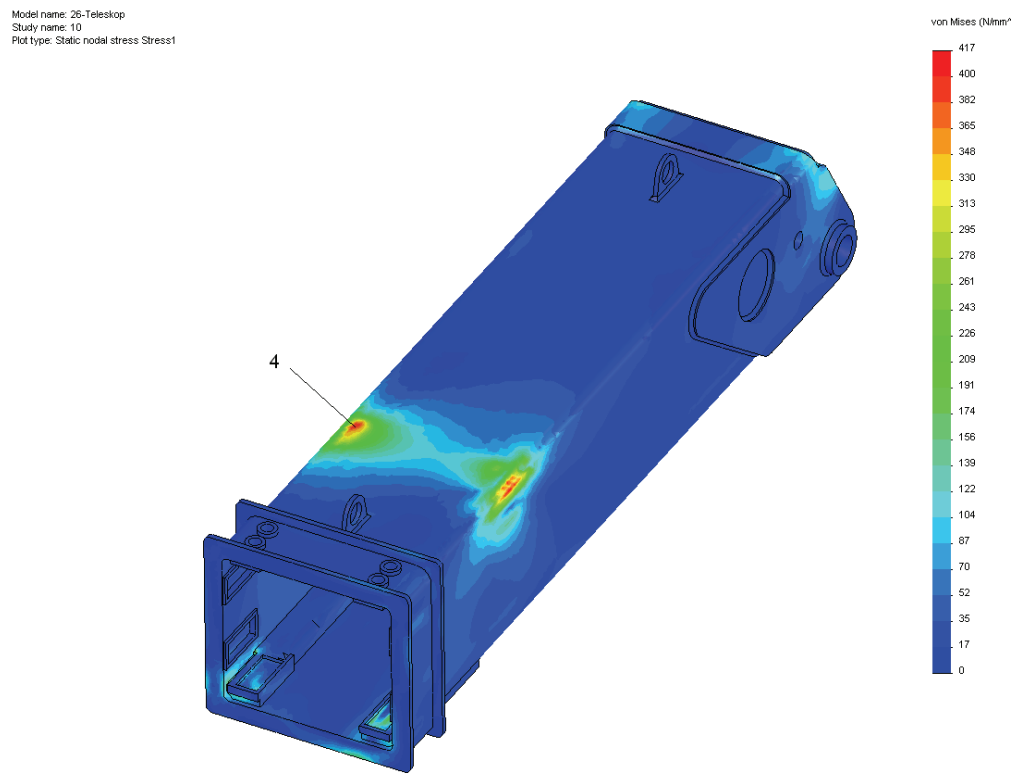

Fig. 2 - Stress analysis of the selected module of working device

\section{VERIFICATION OF THE MACHINES TECHNICAL PARAMETERS}

The results of the optimized structure were verified by measurments on the prototype. Verification of the designed parameters are performed based on ISO 14397-1 and ISO 14397-2, concerning tearout verification, lifting forces and over-end load. The process of tearout force, depending on the boom position (after optimization of kinematics) of working device is shown in Fig. 3. The results of measured tearout forces are shown in Fig.4.

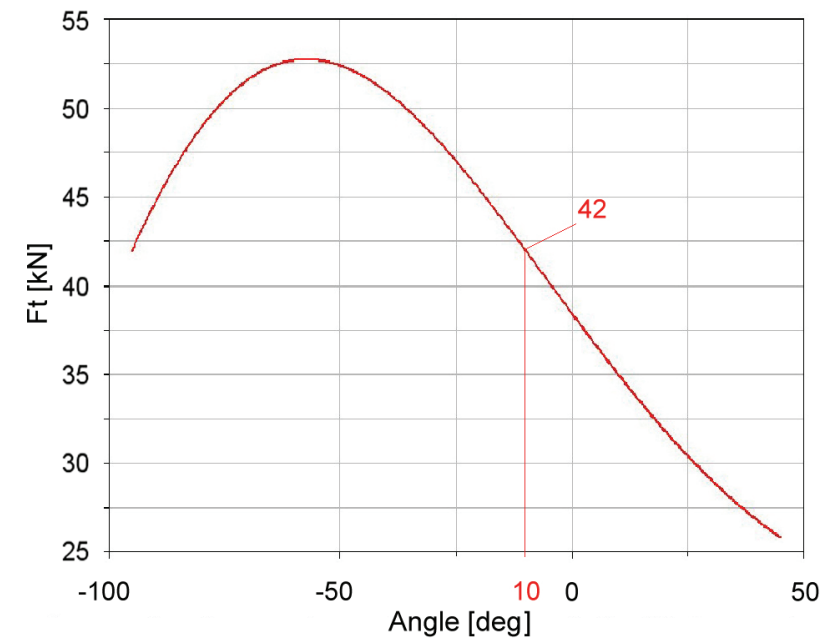

Fig. 3 - The result of optimization - process of tearout strength 
Values obtained from measurements are not significantly different from optimization results. ( analysis $=42 \mathrm{kN}$, measured values $=46 \mathrm{kN}$ ). We can say that results of computer modeling (applies for a well-developed model, loaded by adequate force effects) and measurements in operating conditions do not show a significant difference, [2].

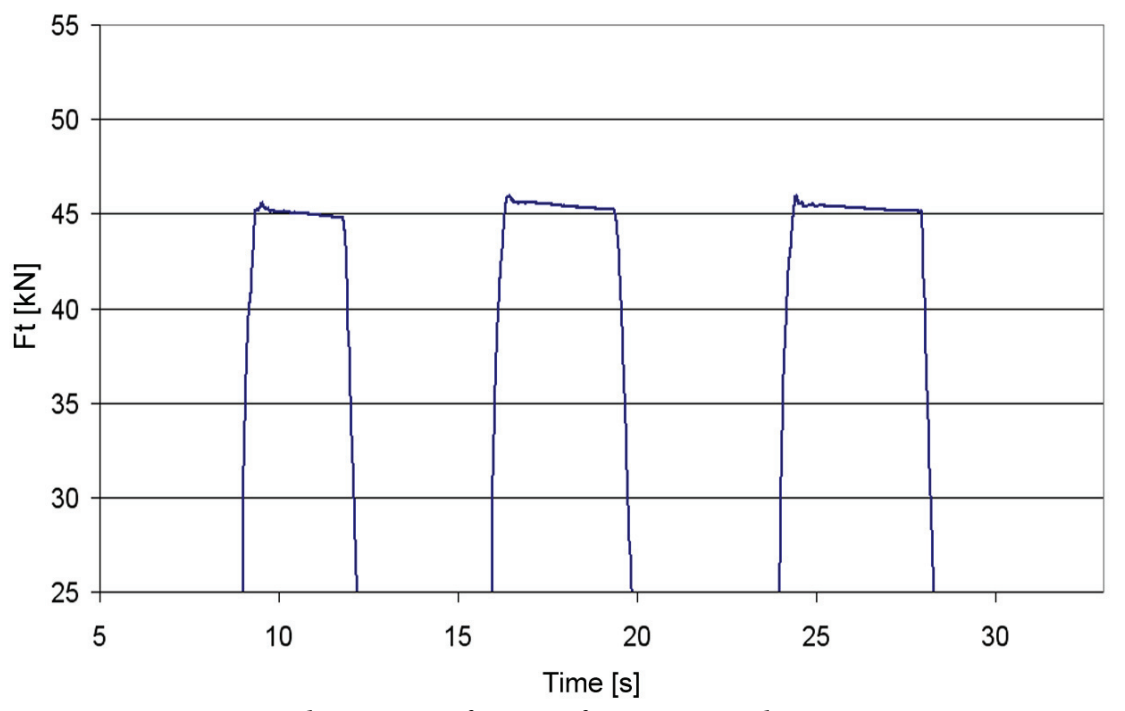

Fig. 4 - The process of tearout force measured on prototype LIFE ESTIMATION OF THE SELECTED MODULE

Service tests performed under the aforementioned standards have the character of static tests. It is necessary to perform operational tests to get an overview of loads occurring in the structure of the machine in operating conditions. Measurements are made during real operating conditions of machine. The time responses of force of performed work technology to critical points of the machine are monitored. Typically these measurements are made at a standard working load, Fig. 5. During machine operation, however, the presence of non-standard loading cannot be excluded, which may have a particular nature. States of this nature may be induced and their influence to the load of the structure may also be determined. Non-standard load can be caused by deliberate overload of the machine or carelessness of the operator.

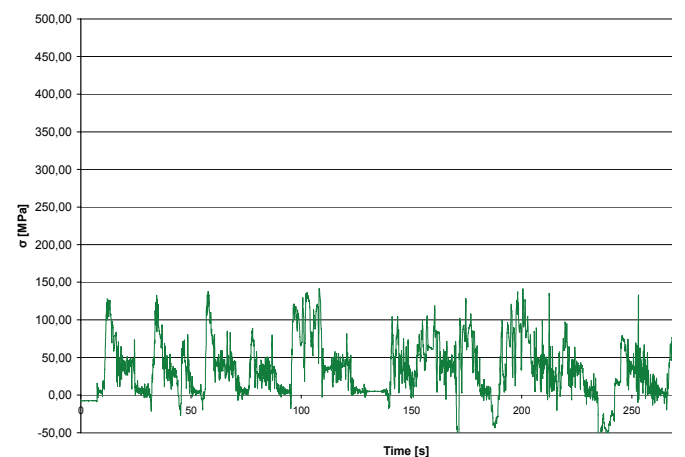

Fig. 5 - Process of loading, typical material handling

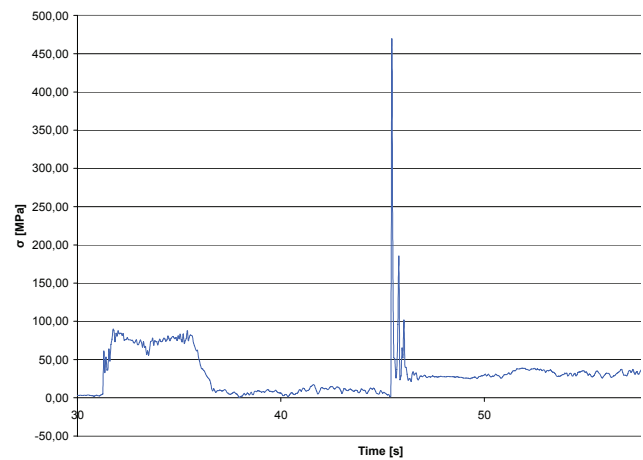

Fig. 6 - Process of loading caused by impact 
Measurements in operating conditions serve as a major source of information for the service life estimation of critical parts. Acquired processes of loads have a generally random character. The value of some parameters of the loading process (maximum amplitude, relative amplitude, mean, crossing levels ...) are determined through various methods of analysis, [4]. Rainflow method is probably the most frequently used method. One method to characterize the service load is definition by the loading spectrum, which is a function of the relative number of occurrences $\mathrm{n}_{\mathrm{i}} / \Sigma \mathrm{n}_{\mathrm{i}}$ versus the relative stress amplitudes, $\sigma_{\mathrm{a}} / \sigma_{\mathrm{ai}} \max$. Fig. 7 shows the loading spectrum of the operating in standard conditions (Fig. 5 Typical material handling) and Fig. 8 shows the loading spectrum considering unexpected overload. The effect of overload (caused by an impact, Fig. 6) is significantly reflected in the load spectrum. The result is a significant decrease in the lifetime estimated by hypothesis. Load spectra arranged on the basis of loading process of loader manipulating different materials have a log-normal distribution.

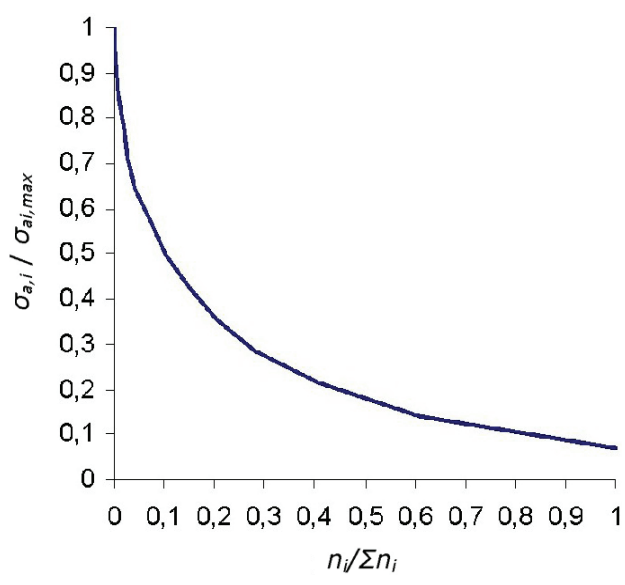

Fig. 7 - Unified loading spectrum ("standard mode ")

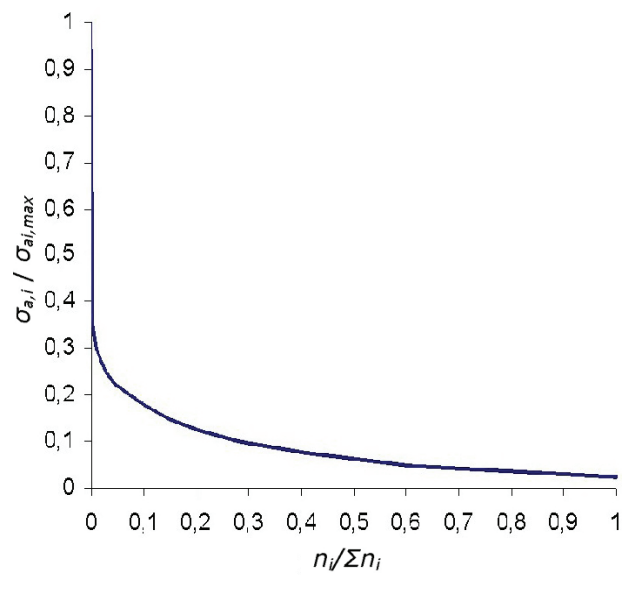

Fig. 8 - Unified loading spectrum ("non-standard loading - impact")

Different hypotheses can be used to estimate the fatigue lifetime. Tab. 1 shows the results of the lifetime estimation by the most frequently used hypotheses such as Palmgren-Miner, Serensen-Kogajev, Corten-Dolan, Haibach [3]. Estimated lifetimes represent the mean values i.e. on the level of $50 \%$ probability. Considering the overloads the mean values of estimated lifetimes becomes modified, see Tab. 1 . 
SCIENTIFIC PROCEEDINGS 2011, Faculty of Mechanical Engineering, STU in Bratislava Vol. 19, 2011, pp. 22-28, DOI: 10.2478/v10228-011-0004-1

\begin{tabular}{|c|c|c|c|c|}
\hline Hypotheses & $\begin{array}{c}\text { Relation for calculating of } \\
\text { lifetime }\end{array}$ & $\begin{array}{l}\text { Estimated } \\
\text { lifetime }\end{array}$ & $\begin{array}{c}\text { Occurrance } \\
\text { of overload } \\
1 / 50 h \\
\end{array}$ & $\begin{array}{c}\begin{array}{c}\text { Occurrance } \\
\text { of overload } \\
1 / 5 \mathrm{~h}\end{array} \\
\end{array}$ \\
\hline Palmgren-Miner & $\frac{n_{1}}{N_{1}}+\frac{n_{2}}{N_{2}}+\ldots \ldots \ldots \ldots \ldots=\sum \frac{n_{j}}{N_{j}}=1$ & $5488[\mathrm{~h}]$ & $4450[\mathrm{~h}]$ & $1646[\mathrm{~h}]$ \\
\hline Serensen-Kogajev & $\sum_{i=1} \frac{n_{j}}{N_{j}}=a \quad a=\frac{\sigma_{a \max } \xi-K \sigma_{c}}{\sigma_{a \max }-K \sigma_{c}}$ & $1100[\mathrm{~h}]$ & $890[\mathrm{~h}]$ & $329[\mathrm{~h}]$ \\
\hline Corten-Dolan & $\sum\left(\frac{\sigma_{a i}}{\sigma_{a \max }}\right)^{d} \frac{n_{i}}{N_{f \max }}=1$ & $11560[\mathrm{~h}]$ & $216[\mathrm{~h}]$ & $199[\mathrm{~h}]$ \\
\hline Haibach & $\begin{array}{l}\mathrm{D}_{\mathrm{c}}=\mathrm{D}_{1}+\mathrm{D}_{2} \\
D_{1}=\frac{\left(\sum_{i} n_{i} \cdot \sigma_{a i}^{k}\right)}{\left(N_{c} \sigma_{c}^{k}\right)} D_{2}=\frac{\left(\sum_{i} n_{i} \cdot \sigma_{c}^{(2 k-1)}\right)}{\left(N_{c} \cdot \sigma_{c}^{(2 k-1)}\right)}\end{array}$ & $10655[\mathrm{~h}]$ & $1257[\mathrm{~h}]$ & $137[\mathrm{~h}]$ \\
\hline
\end{tabular}

Tab 1 - Fatigue life estimated by particular hypotheses

The results obtained by various hypotheses show a considerable dispersion. Therefore, for estimation of operational life it is important to select a suitable hypotheses. Selection and results as well are influenced by the nature of the loading. The phenomenological hypotheses show different sensitivity to overloads. Corten-Dolan's and Haibach's hypotheses prefer the overloads significantly. Others prefer monotonic function of the load spectra. Nonetheless suitability of the selected hypotheses and information obtained by laboratory testing confirms the real service of working machine. 


\section{CONCLUSION}

An important stage in the development of a new design is to ensure reliability during its planned operational life. One of the criteria of reliability is the endurance of critical points of structure, influencing the lifetime of the whole structure. Hypotheses of fatigue damage, taking into account the nature of the operational loads, are applied to estimate the service lifetime. The load spectra are generally determined on the basis of measurements on prototypes, or similar structures operating in the expected operating conditions. Reliability of the results of the estimate depend on the load spectrum representing the operating load and also choice of suitable hypothesis of fatigue damage cumulation.

\section{REFERENCES}

[1] PALČÁK, F. - PRESINSZKÝ G. - HÓK, V. - MAZURKIEVIČ. I.: The construction of mechanism working equipment of loader in the MSC.ADAMS program. New Trends in design and creation of technical documentation, 2008, Nitra, proceedings, May 2008

[2] JÁNOŠÍK, L'. - IZRAEL, G. - GULAN, L. - MAZURKIEVIČ. I.: Verification of basic technical parameters of the loader weight class 2t. In: Lifting Equipment in theory and practice: Proceedings of professional Conference with international participation. - Tatranska Lomnica, 9-10.10 2008th - Košice: Technical University of Kosice, 2008. - ISBN 978-80-5530071-9. - S. 57-62

[3] SERENSEN, V. S. - KOGAJEV, V.V. - ŠNEIDEROVIČ, M.R.: Únosnost a pevnostní výpočty strojných součástí, STNL-PRAHA 1967, 04-224-67

[4] ZÁCHENSKÝ, P., BUKOVECZKY, J.: Database of load spectra of construction machinery aggregates. Summer school of material fatigue '94, Zilina-Rajecké Teplice, ES VŠDS Zilina, September 1994 